\title{
NOTAS SOBRE LA VEGETACIÓN DE EXTREMADURA (ESPAÑA)
}

\author{
M. LADERO *
}

\section{RESUMEN}

En el presente trabajo se realiza un bosquejo sobre la vegetación potencial y las etapas de sustitución actuales observadas en Extremadura. Se indican las influencias florísticas observadas en la flora extremeña y la incidencia que ella ha podido tener sobre la comarca vecinal. Finalmente, señalamos algunas plantas que definen perfectamente las formaciones vegetales encontradas en la región.

\section{SUMMARY}

This research work synthesizes a study of the vegetation of the Extremadura region and its possible influence on the nearly geographical areas. This paper also includes a study where the characteristic species of the potential vegetation there as well as the different periods of vegetal growth, located in that region, are defined and classified.

La Península Ibérica situada en la ribera occidental del Mediterráneo, reúne unas condiciones ecológicas tales que hacen de ella un verdadero paraíso para los botánicos y zoólogos, únicamente comparables con Asia Menor en la ribera oriental.

Como consecuencia de su privilegiada situación geográfica, ha sentido la influencia de las floras circundantes, siendo en el momento actual y en épocas no lejanas un verdadero mosaico, donde tienen representación la fiora de las regiones colindantes. En esta península se ponen en contacto desde la vegetación macaronésica y norteafricana árida hasta la eurosiberiana; e incluso como consecuencia de ciertas concordancias climáticas, aparecen en las altas parameras ibéricas los bosques de cupresineas, semejantes a las que se encuentran en las llanuras de Anatolia. Pero la que ocupa mayor extensión es la vegetación mediterránea, llegando incluso a presentarse en diversos enclaves del litoral cantábrico en pleno dominio de la flora atlántico-centroeuropea.

* Departamento de Botánica. Facultad de Farmacia. Universidad Complutense. Madrid-3. 
La vegetación potencial de la Iberia mediterránea corresponde a un bosque perennifolio, que lleva como árboles directrices a las encinas (Quercus rotundifoliae Lam. y Quercus ilex L.), a los que acompañan según las condiciones ecológicas Quercus suber L., y Quercus faginea Lam., este último elemento semicaducifo.io y vicariante de Quercus infectoria Olivier de ciertos puntos de Grecia y Turquía.

Si importancia tiene el factor climático, no es menor la del edáfico lo cual nos lleva a diferenciar dentro de la región mediterránea dos zonas, silícea y caliza dependiendo del sustrato.

La España mediterránea silícea qucda incluida dentro del gran Macizo Ibérico que se levanta predominante en la mitad occidental de la Península, discurriendo en su mitad oriental bajo los estratos mesozoico-terciarios y haciéndose únicamente visible en las grandes elevaciones montañosas de Sierra Nevada, Pirineos y la Cordillera litoral Catalana.

Para poder llegar a comprender esta vegetación mediterránea silícea, nada mejor que tratar sobre la vegetación de una región española como es Extremadura. La región extremeña ubicada en el cuadrante suroccidental de la Península Ibérica, presenta influencia característica de las zonas colindantes, pero ella a su vez ha influido de forma decisiva en la vegetación de las mismas, de aquí que la consideremos como centro de irradiación por una parte y por otra de tránsito para algunos taxones y ciertas comunidades vegetales.

La proximidad del océano ha influido de forma decisiva en la constitución cuantitativa de ia vegetación y flora de las sierras graníticas norooccidentales, como son Gata y San Mamede. Aunque fisognómicamente están cubiertas por robledales de Quercus pyrenaica Willd., en las etapas de sustitución a nivel de matorral se ven enriquecidas por elementos propios de las provincias noratlánticas, entendiendo como tal el norte de Portugal y Galicia. Como taxones más representativos señalamos los siguientes: Ulex minor Roth., Simethis planifolia (L.), Hoffmanns \& Link, Coutinho, Agrostis setacea Curt., Lithodora diffusa (Lag.) I. M. Johnst., subsp. lusitanica (Samp.) P. Silva \& Rozeira, Pedicularis sylvatica L. subsp. lusitanica, Thymus caespititius Brot, etc.; presentando en la Sierra de Gata como diferencial el bello endemismo Thymelaea procumbens A. \& R. Fernandes.

No podemos dejar de seña'ar la influencia que ejerce en el vértice suroccidental de Extremadura, ia climatología del Cabo de San Vicente y el Golfo de Cádiz, lo cual, queda de manifiesto por los gigantescos alcornoques que cubren sus ramas con el color verde grisáceo de los líquenes foliáceos y fruticulosos y sus troncos con el verde intenso del estrato 
muscinal. En ciertos valles de la Sierra del Oratorio (Badajoz) como consecuencia de las persistentes nieblas invernales, las dehesas arboladas adquieren toda su grandeza, recordando a las que se asientan en zonas más meridionales y próximas al mar como ocurre en la provincia de Cádiz. Esta influencia oceánica disminuye al subir en latitud, teniendo su último testigo en el Drosophyllum lusitanicum (L.) Link de la Sierra Fría de Valencia de Alcántara (Cáceres). En mi opinión los alcornocales tienen un marcado carácter subatlántico presentando su óptimo de vitalidad en la provincia corológica gaditano-a!garbiense. Inmediatamente podemos pensar en el porqué de los aicornocales interiores, tanto de la penillanura como de los pisos serranos de nuestras serranías. La aparición de los alcornocales en las zonas bajas, se hace sobre depósitos pliocenos, donde aunque escasa y mediante un proceso de geyzación se acumula el agua a profundidades medias, con lo que queda compensado el aporte hídrico. Indudablemente disminuyen los líquenes epífitos debido al menor número de días de niebla. Como elementos característicos y diferenciales de los alcornocales asentados en las penillanuras destacamos las dos vistosas lialiaceas Ornithogalum unifolium Gawl, y Scilla monophylla Link.

Los alcornocales que tapizan las serranías silúricas de la región extremeña por debajo de los $900 \mathrm{~m}$ hay que buscar su origen en los alcornocales de las zonas más meridionales, aunque por su empobrecimiento, han adquirido un carácter típicamente extremeño. Como elementos diferenciales de estos alcornocales serranos destacamos Sanguisorba hybrida (L.) Nordborg, Magydaris panacifolia (Vahl) Lange, Airopsis tenella (Cav.) Coss \& Dur.

El límite suroriental de la región extremeña ha sido el área de penetración de la flora bética termófila, que se extiende de forma continua por debajo de los 460 m.s.n.m. en una amplia banda de la provincia pacense. Tiene siempre el aspecto de "charnecal" llegando a su óptimo en los riberos del río Ardila con la presencia de la palmera enana o palmito (Chamaerops humilis L.). Hacia el norte, la vegetación termófila se asienta como comunidad permanente de solana en los abruptos riberos de los ríos servidores del Tajo y del Guadiana. Esta comunidad queda bajo el aspecto de "acebuchal" cuando el suctrato son pizarras cámbricas y de "lastonar" en las zonas graníticas. Los "acebuchales" (formaciones densas de Olea europaea L. var. oleaster (Hoffmanns \& Link) DC.) parecen tener su óptimo en la provincia gaditana, de donde han irradiado a Extremadura para luego después llegar a ciertos puntos de la cuenca del río Duero como Barca de Alba, Saucelle, La Fregeneda, etc. Por el contrario, la variante con almeces o latoneros (Celtis australis L.) puede ser considerada como más mesofítica, teniendo su máxima representación en las proximidades de la 
Presa de Aldeadávila (Salamanca). El área ocupada por los acebuchales en Extremadura coinciden casi totalmente con los ahijaderos de ganado lanar, que fueron creados por los romanos teniendo en el momento actual un nuevo período de esplendor.

La influencia de la Meseta inferior pasa casi inadvertida y únicamente en los crestones de las alineaciones silúricas orientales se dibuja una pequeña banda de encinares con enebros (Juniperus oxycedrus L.) y que representan la vegetación más continental de todo el territorio. Compartiendo el mismo habitáculo que los taxones anteriormente mencionados se encuentra la Genista cinerea (Vill.) DC. subsp. cinerascens (Lange) RivasMartínez y Adenocarpus hispanicus (Lam.) DC. subsp. argyrophyllus Rivas Goday que marcan la continentalidad.

Finalmente, las sierras extremeñas que superan los $900 \mathrm{~m}$ s.n.m. se cubren con bosques caducifolios que tienen como base florística la Quercus pyrenaica Willd., siendo los testigos de la influencia carpetano-leonesa, así como zona de paso para el asentamiento de los robledales en Sierra Madrona y Sierra de Aracena dentro de la Cordillera Mariánica. Indudablemente estos robledales son más térmicos que los del Sistema Central, lo cual se traduce en la aparición de ciertos táxones diferenciales tales como Leuzea rhaponticoides Graells, Allium massaessylum Batt. \& Trab. etc.

Una vez destacadas y comentadas las influencias que en Extremadura tiene la vegetación y flora de las zonas colindantes, pasamos a señalar las que en mi forma de observar el campo me parecen típicamente extremeñas, siendo considerada tal vez como centro de irradiación.

Así como Portugal es el país de los matorrales, producto de una desforestación anárquica con fines agrícolas, Extremadura puede ser considerada como el país de las dehesas con fines ganaderos. Estas pueden ser arboladas o desforestadas, llamándose en el primero de los casos monte hueco y donde tiene una importancia fundamental el tipo de sustrato ya sean granitos, pizarras precámbricas, pizarras silúricas, etc. $\mathrm{Me}$ estoy refiriendo a la penillanura extremeña.

La vegetación potencial corresponde a encinares con influencia subatlántica y donde la planta más característica a parte de la encina, es el piruetano o galapero (Pyrus bourgeana Decne.). Las etapas de sustitución ya sean matorrales, tomillares o pastizales, marcan aún mejor si cabe el tipo de sustrato sobre el que ce desarrollan. En las zonas berroqueñas de la penillanura generalmente ais'adas, se cobijan los típicos escobonales blancos de Cytisus multiflorus (L'Her.) Sweet y a las que acompaña plantas tan interesantes como Adenocarpus complicatus (L.) Gay subsp. commutatus (Guss.) Coutinho y Ornithogalum coccinium Sal. etc. Este último 
taxon caracteriza a los escobonales en el comienzo de la primavera y puede ser considerado como elemento vicariante frente al Ornithogalum unifolium, que se desarrolla en los a'cornocales sobre los sedimentos silíceosterciarios. En cuanto a los tomillares, como consecuencia de la textura de las tierras pardas meridionales de fácil erosión, cada día ocupan estas comunidades nanofruticosas mayor extensión, estando en general representadas por Lavandula pedunculata Cav., Thymus mastichina L. y la medicinal cebolla albarrana Urginea maritima (L.) Baker.

Si las formaciones graníticas ocupan áreas bastante extensas en nuestra región, no es menor la superficie de las pizarras precámbricas que dan al paisaje un aspecto especial. Debido a la eutrofía de las tierras pardas meridionales que originan, grandes extensiones se encuentran desarboladas y dedicadas a los cultivos cerealistas desde que España fue considerada como el granero de Roma. El roturado indebido de las laderas más o menos escarpadas y el posterior arrastre por ias lluvias de estos suelos, ha provocado la aparición de suelos esqueléticos (litosuelos), donde únicamente se desarrollan tomillares. Por el contrario, si se hace un descolinado adecuado da lugar a la aparición de pastizales eutrofos, siempre y cuando estos sean aprovechados por ganado lanar o vacuno. Cuando las praderas naturales son pastoreadas de una forma intensiva, dan lugar al embastecimiento de las mismas, con la aparición de algunas plantas tales como la Urginea maritima (L.) Baker en los llanos y en los altozanos y por el contrario la aparición de los gamones en las depresiones. En resumen los tomillares son la expresión más auténtica de las penillanuras precambrianas y donde el color morado de las cabezuelas de los cantuesos (Lavandula pedunculata Cav.) contrasta con el color grisáceo de los pizarrales. Es en estas zonas, donde las pizarras miran al cielo como si siempre imploraran agua.

La sequía casi permanente de las penillanuras cámbricas es debida a dos causas derivadas la una de la otra, el escaso grosor de los suelos y la nula capacidad de retención de la roca madre, por donde el agua resbala como si de asfalto se tratara. Finalmente en las penillanuras son muy escasas las cistáceas sobre todo en cuanto a Cistus ladaniferus L. siendo ocupado su lugar en la serie por las matas de encina formando lo que dominamos "mata parda". 


\section{BIBLIOGRAFIA}

Ladero, M. 1967. Especies interesantes del Macizo de las Villuercas (Cáceres). Anal. Inst. Bot. Cavanilles, 25:277-286, Madrid.

LAdERo, M. 1970. Contribución al estudio de la flora y vegetación de las comarcas de La Jara, Serranía de Ibor y Guadalupe-Villuercas, en la Oretana Central (Tesis Doctoral).

Ladero, M. \& Izco, J. 1970. Aspectos geobotánicos sobre el acebuche y el olivo, en la Península Ibérica, Monitor de la Farmacia núm. 1963, Madrid.

Rivas Goday, S. 1964. Vegetación y flórula de la cuenca extremeña del Guadiana, Madrid.

Rivas Goday, S. \& Ladero, M. 1970. Pastizales cespitosos de Poa bulbosa L. (Origen, sucesión y sistemática). Anal. R. Acad. Farm. 36(2):140-181, Madrid.

Rivas Goday, S. \& Ladero, M. 1973. Nuevas aportaciones a la flora pacense. Anal. R. Acad. Farm. 39(3):267-284, Madrid.

Rivas-Martínez, S. 1974. La vegetación de la clase Quercetea ilicis en España y Portugal. Anal. Inst. Bot. Cavanilles, 31(2):205-259, Madrid.

Rivas-MartíneZ, S. 1975. Mapa de vegetación de la provincia de Ávila. Anal. Inst. Bot. Cavanilles, 32(2):1493-1556, Madrid.

(Recibido el 4 de diciembre de 1977) 